\title{
APPLICATION OF ASSOCIATION RULE MINING AND MINING SEQUENTIAL PATTERNS ON CRM PT. ARMADA INTERNATIONAL MOTOR
}

\author{
Nina Setiyawati \\ Dosen Universitas Kristen Satya Wacana \\ Email: ninasetiyawati@gmail.com
}

Diterima: 2 Januari 2018/ Disetujui : 19 Januari 2018

\begin{abstract}
Keeping in touch with customers is a step that must be done by the company to increase customer loyalty. CRM is a set of processes to acquire, maintain and enhance the values for customer satisfaction for the continued growth of corporate profits. With data mining for extracting knowledge, performance can be improved CRM in obtaining information about customers. In this study, carried out by the application of CRM design Association rule mining and sequential pattern mining techniques to provide recommendations to the customer service type PT Armada International Motor. CRM is built based mobile and able to provide effective services and recommendations for customers.
\end{abstract}

Key words : CRM, Association Rule Mining, Sequential Pattern Mining

\section{INTRODUCTION}

Customers is an important component of a business, understanding the factors on the development of a sense of loyalty to customer management issues crucial issue at this time $[1,2]$. Retain customers and increase loyalty is a very important financial activity in a company because it is much more expensive costs to attract new customers [3,4]. By increasing the strength of the relationship with the customer, companies can increase profits [5,6]. Customers will also be dependent on the company and the possibility of switching to offer lower prices than competitors will be reduced [6], so that the customer will last longer and is associated with the company then the company will boost profit [7].

PT. Armada International Motor is one of the company's automotive distributor in Indonesia, which has a sales division and a workshop division. Indonesian automotive market competition increasingly competitive automotive distributor companies make every race get market. Build customer loyalty [8] and develop a sustainable competitive advantage [9] is seen as a key factor to gain market share. Customer Relationship Management (CRM) is the right method to be applied as the two key factors. CRM is a combination of marketing, sales and service organization for the purpose of knowing the customer, understand their needs, determine the combined products and services are best for them, as well as providing services and values that will increase profitability and strengthen customer relationships [3]. It can be concluded that based on customer information, CRM utilizing it to maintain good relations with customers [10].

Given the fact that retaining customers is a very important thing, then PT. AIM requires the application of CRM to the process of development of the company and increase profits. Workshop division is the division that provides gross profit as much as $60 \%$ of the company and possess the intensity of the relationship to the customer $70 \%$ more than the sales division is the proper division for implementing CRM. PT data mining workshop. AIM will get the customer data, the implementation of the service history, and the type of service performed. However, customers do not have the service history data and the type of service that has been done. This will result in incorrect time schedule customer service and random execution of the service types.

Type of service that the schedule service is an important factor in the care of the vehicle. There are several types of service are related to one another and schedule service is an important factor in determining the type of service performed sequentially. By using data mining is a step in the process of Knowledge Discovery in Databases which consists of applying data analysis and discovery 
algorithms that produce a particular enumeration of patterns over the data [11], PT. AIM can provide recommendations based on type of service related data service implementation from other customers as well as schedule service reminders to customers along with type of service that should be done based on the implementation of the service history that has been done.

With association rule mining, could be sought relationships between different items in a dataset in which the different data on the transaction resulting in a different grouping [2,12]. Transaction data service types that already exist in the database will be excavated and found to be grouped so that the distribution pattern of the entire dataset, so that the resulting recommendation service types are interconnected.

As for the schedule of service and type of service that should be done based on service history, that has been done is used a sequential pattern mining is an active data mining domain dedicated to sequence data [13].

Combined Association rule mining and sequential pattern mining are integrated in the CRM PT. AIM-based internet that can be accessed by employees of PT. AIM and the customer so that the customer can know the service schedule, service history, and recommendation service that should be done with the schedule reminder service via mobile devices.

\section{REVIEW OF LITERATURE}

\section{A. Customer Relationship Management}

One of the essential requirements in the advancement of the company is to understand what customer needs. CRM is the values and strategies of relationship marketing - with particular emphasis on customer relationships - turned into practical applications [14], which will focus on the process of acquiring, retaininng, and increase customer profits [15]. So CRM focuses on how to identify the best customers and maximize enterprise value of the customer and maintain a satisfactory manner [16]. Model of the relationship of each element of CRM objectives shown in Figure 1.

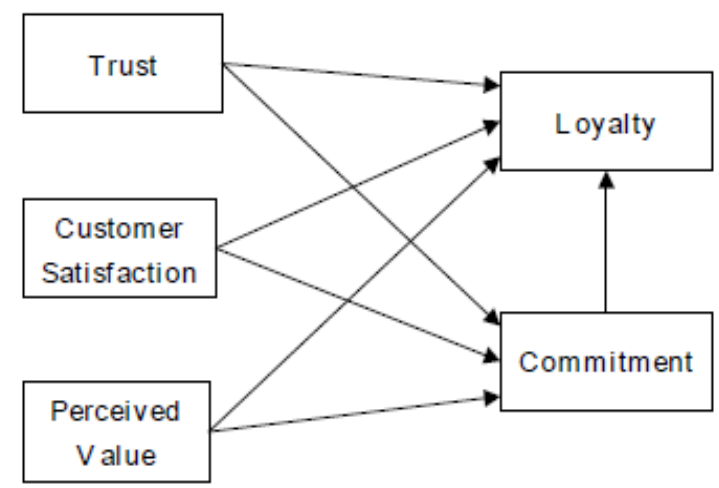

Figure 1. The Purpose of CRM Elements [17]

Figure 1 shows that the purpose of CRM is trust, customer satisfaction, perceived value, comitment, and loyalty. Trust of customers will give customers comitment to the company and the company will earn the loyalty of customers. Also when the customer is satisfied and get the value of a product, they will be committed to a company and give their loyalty to the company. Comitment of every customer will get the highest loyalty to the company. If the customer has committed and give loyalty to the company, the customer will not be affected by another product even offering low prices.

From the definition above, it can be concluded as follows:

- CRM is an industry term for methodologies, strategies, software (software) and or other web-based applications that can help a company (enterprise, if large in size) to manage relationships with customers,

- CRM is an enterprise effort to concentrate on keeping the customer (so as not to run into a competitor) to collect all forms of customer interaction whether it is by phone, email, feedback on the site or the outcome of talks with the sales and marketing staff,

- CRM is a comprehensive business strategy of a company that enables companies to effectively manage relationships with customers. 


\section{B. Data Mining}

Data Mining or Knowledge Discovery in Databases (KDD) is the implicit filtering of the data where the presence of previously unknown information potential [17]. Process-the process of knowledge extraction on Knowledge Discovery in Databases (KDD) shown in Figure 2.

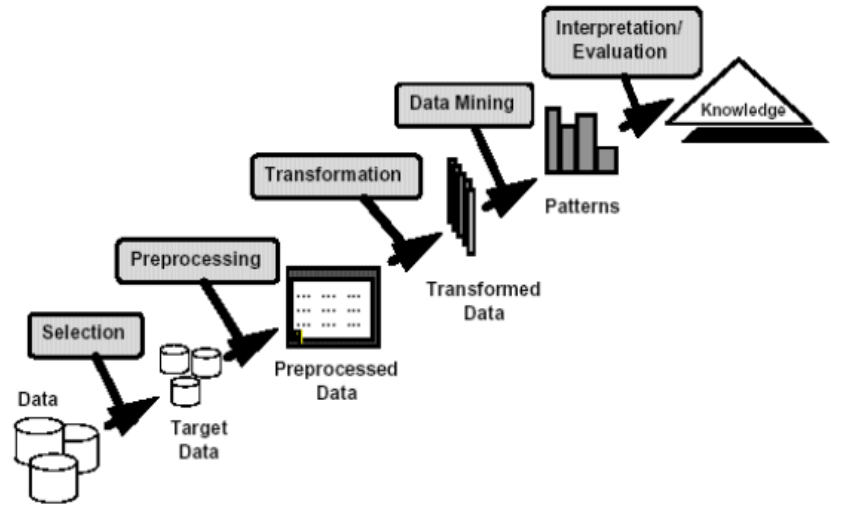

Figure 2. The process of Knowledge Discovery in Database [11]

In Figure 2 shows that the data that has been through the stages of selection, preprocessing and transformation will be explored so that the discovered patterns of data that can then be interpreted into knowledge. In data mining, there are two modes, namely the description and forecasting. A model description to identify patterns or relationships in the data. While the forecasting model to make predictions about the value of data using known results found from different data [18].

\section{Association Rule Mining}

Important type of patterns that can be found from the data base is a rule. Association rule has the form LHS RHS with interpretation if every item in the LHS purchased the item in the RHS seems also purchased. Two measurements are important for a rule support and confidence. We can enumerate all association rules with support and confidence threshold the user enter the postprocessing frequent-item set.

Generally Association Rule has the form: LHS RHS, where LHS and RHS is the set of items: if any items in the LHS of the transactions contained in the items on the RHS is also included in the transaction. There are two rules for the measurement of association rule [12]:

\section{Support}

Support for the set of items is the percentage of transactions that contain all of these items. Support for the rule LHS RHS on-set support for LHS RHS items.

\section{Confidence}

Consider transactions that contain all items in the LHS. Confidence for the rule: LHS RHS is the percentage of transactions that also comprises all the items in the RHS. More precisely, let sup (LHS) is the percentage of transactions that contain and soup LHS (LHS RHS) is the percentage of transactions that contain the LHS and RHS, then the confidence rule: LHS RHS is sup (LHS RHS) / $\sup ($ LHS).

Association Rule problems can be composed into two sub-problems, namely:

1. The discovery of all combinations of items, called frequent-item set, whose support is larger than the minimum support.

2. Use frequent-item set to generate the desired rules. $\mathrm{Eg} A B C D$ and $A B$ appears frequently in the transaction, then the rule $A B C D$ will be met if the ratio between support ( $A B C D$ ) to support $(A B)$ minimum minimum confidence. All the rule will have minimum support because ABCD often appear in the transaction.

\section{Sequential Pattern Mining}

Sequential Pattern mining is a topic of data mining concerned with finding statistically relevant patterns between data examples where the values are delivered in a sequence.It is usually presumed that the values are discrete, and thus time series mining is closely related, but usually 
considered a different activity. Sequential pattern mining is a special case of structured data mining. There are several key traditional computational problems addressed within this field. These include building efficient databases and indexes for sequence information, extracting the frequently occurring patterns, comparing sequences for similarity, and recovering missing sequence members. In general, sequence mining problems can be classified as string mining which is typically based on string processing algorithms and item set mining which is typically based on association rule learning [13].

\section{DISCUSSION}

Development of Internet-based CRM PT.AIM and can be accessed through mobile devices. Used association rule mining to recommendation type of service and sequential pattern mining to schedule service and recommendation service based on service history. Recommended types of service performed when a customer has been in the garage to do the service. Based on the data service that already exists, the pattern found is used to provide recommendations to the customer. There is the data as shown in Table 1.

Table 1 Transaction Data

\begin{tabular}{|l|l|}
\hline \multicolumn{1}{|c|}{ TID } & \multicolumn{1}{|c|}{ Item set } \\
\hline 1 & $\begin{array}{l}\text { A.Ganti Oli Mesin, C.Ganti Oli } \\
\text { Transmisi, D.Ganti Minyak Rem }\end{array}$ \\
\hline 2 & $\begin{array}{l}\text { B. Ganti Oli Gardan, C. Ganti Oli } \\
\text { Transmisi, E. Tune Up }\end{array}$ \\
\hline 3 & $\begin{array}{l}\text { A. Ganti Oli Mesin, B. Ganti Oli } \\
\text { Gardan, C.Ganti Oli Transmisi, } \\
\text { E.Tune Up }\end{array}$ \\
\hline 4 & B.Ganti Oli Gardan, E. Tune Up \\
\hline
\end{tabular}

Association rule algorithm is as follows:

1. Determine minimum support $50 \%$

2. Looking for large 1-item set

\begin{tabular}{|l|l|}
\hline Item set & Support \\
\hline A & $50 \%$ \\
\hline B & $75 \%$ \\
\hline C & $75 \%$ \\
\hline D & $25 \%$ \\
\hline E & $75 \%$ \\
\hline
\end{tabular}

3. Looking for a candidate item set L2:

- Combine item set in L1 (apriori-gen algorithm)

$\{\mathrm{A} \mathrm{B}, \mathrm{A} \mathrm{C}, \mathrm{A} \mathrm{D}, \mathrm{A} \mathrm{E}, \mathrm{B} \mathrm{C}, \mathrm{B} \mathrm{D}, \mathrm{B} \mathrm{E}, \mathrm{C} \mathrm{D}, \mathrm{CE}, \mathrm{DE}\}$

- Remove that do not exist in the item set

Item set $\{\mathrm{B} D, D E\}$ removed because there is no in item set.

4. Count the support of each candidate item set

\begin{tabular}{|l|l|}
\hline Item set & Support \\
\hline AB & \\
& $25 \%$ \\
\hline A C & $50 \%$ \\
\hline A D & $25 \%$ \\
\hline A E & $25 \%$ \\
\hline B C & $50 \%$ \\
\hline B E & $75 \%$ \\
\hline C D & $25 \%$ \\
\hline
\end{tabular}


5. L2 \{ large 2-item set $\}$

\begin{tabular}{|l|l|}
\hline C E & $50 \%$ \\
\hline
\end{tabular}

6. Repeat steps 3-5.

\begin{tabular}{|l|l|}
\hline Item set & Support \\
\hline A C & $50 \%$ \\
\hline B C & $50 \%$ \\
\hline B E & $75 \%$ \\
\hline C E & $50 \%$ \\
\hline
\end{tabular}

- Combine item set in L1 and L2

\begin{tabular}{|l|l|}
\hline Item set & $\begin{array}{l}\text { Hasil Gabungan } \\
\text { (3 item set) }\end{array}$ \\
\hline A C + B C & A C B \\
\hline A C + B E & A C B, A C E, A B E \\
\hline A C + C E & A C E \\
\hline B C + B E & B C E \\
\hline B C + C E & B C E \\
\hline B E + C E & B C E \\
\hline
\end{tabular}

- Remove that do not exist in the item set : $\{$ A C E $\}$

7. Count the support of each candidate item set L3

8. L3 \{ large 3-item set $\}:\{B$ C E $\}$

\begin{tabular}{|l|l|}
\hline Item set & Support \\
\hline A B C & $25 \%$ \\
\hline A B E & $25 \%$ \\
\hline B C E & $50 \%$ \\
\hline
\end{tabular}

There is interconnected item set that satisfies the minimum support $\{\mathrm{BCE}\}$ or axle oil change, transmission oil change and tune up. So if there is a customer going to do the oil change service axle and transmission oil change, the system will suggest to do this type of service tune up.

While sequential pattern mining will be applied to the application of the schedule service reminders and recommendations based on the type of service history kind of service that has been done by the customer. There is the data as shown in Table 2 .

Table 2. Database Based on Customer Id and Date

\begin{tabular}{|c|c|c|}
\hline Customer ID & Date of Service & Type of Service \\
\hline MGL1702 & 23 Desember & A,B,E \\
MGL1702 & 2012 & C,D,E \\
MGL1702 & 22 Maret 213 & A,B,D,E \\
& 23 Juni 2013 & \\
\hline MGL1818 & 13 Mei 2013 & A, E \\
MGL1818 & 15 Agustus 2013 & B,D \\
\hline MGL1823 & 6 Oktober 2012 & A,E \\
MGL1823 & 8 Januari 2013 & B,D \\
MGL1823 & 6April 2013 & B,E,C \\
MGL1823 & 8Juli 2013 & D,E \\
\hline
\end{tabular}

From Table 2 formed sequence database as shown in Table 3. While sequential pattern mining will be engraved on the application of the schedule service reminders and recommendations based on the type of service history type of service that has been done by the customer. There is the data as shown in Table 2. 
Table 3. Sequence Database

\begin{tabular}{|c|c|}
\hline Customer ID & Service Sequence \\
\hline MGL1702 & $\{(\mathrm{A}, \mathrm{B})(\mathrm{C}, \mathrm{D})(\mathrm{A}, \mathrm{B}, \mathrm{E})\}$ \\
\hline MGL1818 & $\{(\mathrm{A}, \mathrm{E})(\mathrm{B}, \mathrm{D})\}$ \\
\hline MGL1823 & $\{(\mathrm{A}, \mathrm{E})(\mathrm{B}, \mathrm{D})(\mathrm{B}, \mathrm{E}, \mathrm{C})(\mathrm{D}, \mathrm{E})\}$ \\
\hline
\end{tabular}

Specified minimum support $25 \%$, so we get the following result.

\begin{tabular}{|l|}
\hline Sequential Patterns with support $>25 \%$ \\
\hline$\{(A, E)(B, D)\}$ \\
\hline
\end{tabular}

From the above explanation was found patterns of sequential type of service. After doing service customers (A, B) it is recommended to perform service $(\mathrm{B}, \mathrm{D})$ at the next scheduled service. Recommendations contained in the reminder application user. The user pages that can be accessed through mobile applications shown in Figure 3.

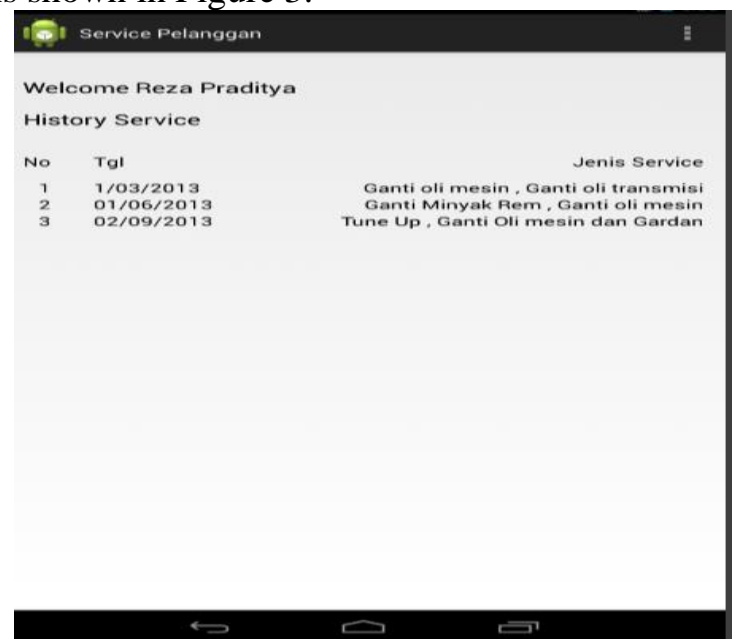

Figure 3. Service History Page

Figure 3 shows the history pages service has been done by the customer. Reminder application is shown in Figure 4.

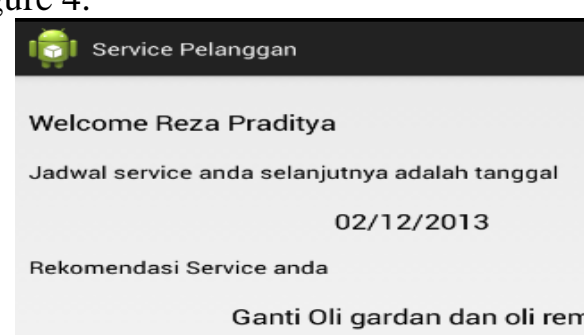

Ganti Oli gardan dan oli rem

\section{↔ 口 च}

Figure 4. Application Reminder 


\section{CONCLUTION}

Based on the issues and the discussion above, we can conclude several points as follows:

1. CRM is able to maintain the quality of the company's relationship with customers through the utilization of information about the customer.

2. With Internet-based CRM PT. Armada Internasional Motor can provide services more effectively and efficiently to customers.

3. Association rule mining and sequential pattern mining are able to produce recommendations to the kind of service customers.

\section{REFERENCES}

[1] Luarn, Pin, Lin, Hsin-Hui, (2003),A Customer Loyalty Model For E-Service Context, Journal of Electronic Commerce Research, VOL. 4, NO. 4.

[2] Khattak, A. M., Khan, A. M., Lee, Sungyoung, Lee, Young-Koo. (2010). Analyzing Association Rule Mining and Clustering on Sales Day Data with XLMiner and Weka. International Journal of Database Theory and Application Vol. 3, No. 1, March, 2010.

[3] Ross, D. F. , (2005), E-CRM from a supply chain management perspective, Journal of Information Systems Management, Volume: 22, Issue: 1, Page 37-44.

[4] Reichheld, F.F. and P. Schefter, "E-Loyalty: Your Secret Weapon on the Web," Harvard Business Review, Vol. 78, No. 4:105-113, 2000.

[5] Reichheld, F.F. \& Sasser, W,E. , Zero defections: quality comes to service, Harvard Business Review, Sep/October 1990, Volume: 68, Issue: 5, Page 105.

[6] Phelps,R.G. (2001), Customer Relationship Management, Thorogood publishing Ltd. London.

[7] Reichheld, F.F. \& Teal, T. (1996), The Loyalty Effect, Harward Business School Press,Boston, Masschusetts.

[8] Jarvis, L.P. and E.J. Mayo, "Winning the Market-Share Game," Cornell Hotel Restaurant Administration Quarterly, Vol. 27, No. 3:72-79, November 1986.

[9] Kotler, P. and R. Singh, "Marketing Warfare in the 1980's," Journal of Business Strategy, Vol. 1, No. 3:30-41, Winter 1981.

[10] Ahmad, Iftikhar, Rahman, Ataur. (2008) Chowdhury Electronic Customer Relationship Management (eCRM). Luleå University of Technology.

[11] Usama Fayyad; Gregory Piatetsky; and Padhraic Smith, From Data Mining to Knowledge Discovery in Database, 1996, AI Magazine.

[12] Agrawal, Rakesh, Srikant, Ramakrishnan. (1994). Fast Algorithms for Mining Association Rules Rakesh. IBM Almaden Research Center. Proceedings of the 20th VLDB Conference Santiago, Chile.

[13] Agrawal, Rakesh, Srikant, Ramakrishnan. Mining Sequential Patterns, IBM Almaden Research Center.

[14] Gummesson, E. (2002), Total Relationship Marketing, second edition, Butterworth Heinemann publications.

[15] Handen, L. (2000). Putting CRM To Work : The Rise of The Relationship. In Stanley A. Brown (Ed.), Customer Relationship Management : A Strategic Imperative in The World of e-Business. New York : John Wiley\&Sons.p.8.

[16] Kennedy, Aileen. (2006). Electronic Customer Relationship Management (eCRM): Opportunities And Challenges in a Digital World. Irish Marketing Review Volume 18 Number $1 \& 2$.

[17] Han, Jiawei. (2006).Data Mining : Concept and Techniques. Second Edition. University of Illinois at Urbana-Champaign.

[18] Adesh Kumar Pandey; V.K Srivastava; A. K Sinha; and S.A.M. Rizvi, 2010, Temperature Prediction Using Heuristic Data Mining on Two-Factor Fuzzy Time Series, www.ubicc.org 